\title{
Short Term Follow up for Diabetic Patients Presented with Acute STEMI Undergoing Preventive Versus Culprit Lesion in Primary Percutaneous Coronary Intervention
}

\author{
Mohamed Elsayed Shuman ${ }^{1}$, Ahmed Abdallah Mostafa ${ }^{2}$, Ghada Mahmoud Soltan ${ }^{3}$, \\ Abdalla Mostafa Kamal ${ }^{3}$ \\ ${ }^{1}$ Cardiology Department, National Heart Institute, Cairo, Egypt \\ ${ }^{2}$ Cardiology Department, Police Academy Center, Cairo, Egypt \\ ${ }^{3}$ Cardiology Department, Faculty of Medicine, Menofia Unversity, Al Minufya, Egypt
}

Email address:

Doctorshuman1981@gmail.com (M. E. Shuman)

To cite this article:

Mohamed Elsayed Shuman, Ahmed Abdallah Mostafa, Ghada Mahmoud Soltan, Abdalla Mostafa Kamal. Short Term Follow up for Diabetic Patients Presented with Acute STEMI Undergoing Preventive Versus Culprit Lesion in Primary Percutaneous Coronary Intervention. Cardiology and Cardiovascular Research. Vol. 3, No. 4, 2019, pp. 99-103. doi: 10.11648/j.ccr.20190304.15

Received: November 2, 2019; Accepted: November 23, 2019; Published: December 4, 2019

\begin{abstract}
Objectives: This study aimed to evaluate the short term follow up for diabetic patients presented with acute STEMI underwent preventive percutaneous coronary intervention. Background: preventive PCI appears to be safe as culprit artery PCI with effective reduction of refractory angina and repeated revascularization in selected patients but no benefit on mortality or recurrent MI. Methods: Our study was a prospective, observational study conducted at multicenter hospitals included 120 diabetic patients admitted with acute STEMI and multivessels CAD at National Heart Institute, Menofia university hospital, police academy center and some private hospitals patients from June 2017 to august 2018, group (A) Consisted of 70 diabetic patients with acute STEMI undergone preventive PCI in whom PCI will be done for culprit \& non culprit lesions, group (B) Consisted of 50 diabetic patients with acute STEMI undergone PCI for culprit lesion only. Results: The total revascularization group were significantly less suffering from refractory angina $5(7.1 \%)$ vs $15(30.0 \%), p=<0.001$ and less re-hospitalized for cardiac causes $14(20.0 \%)$ vs $22(44.0 \%), p=0.005$, cardiac mortality was 2 patients $0(0.0 \%)$ vs 2 (4\%) $p=0.092$. Conclusion: The preventive PCI appears to be safe as culprit artery PCI with effective reduction of refractory angina and repeated revascularization but no benefit on mortality or recurrent MI in selected hemodynamically stable STEMI diabetic patients with multivessel disease.
\end{abstract}

Keywords: STEMI, Multivessels CAD, Preventive PCI

\section{Introduction}

There is strong evidence demonstrating greater risk for ASCVD with increasing dysglycemia, with an estimated $11 \%$ to $16 \%$ increase in cardiovascular events for every $1 \%$ increase in HbA1c [2]."

Multiple cellular and molecular pathophysiologic factors participate in ASCVD, creating the "perfect storm" for atherosclerosis. Patients with type 2 diabetes mellitus have greater atherosclerotic plaque burden, higher atheroma volume, and smaller coronary artery lumen diameter than persons without diabetes mellitus. Although numerous processes may contribute to ASCVD in diabetes mellitus,
Primary percutaneous coronary intervention (PCI) is currently the reperfusion treatment of choice in acute STsegment elevation myocardial infarction (STEMI), In patients with ST-segment elevation myocardial infarction (STEMI), timely treatment with primary percutaneous coronary intervention (PCI) is recommended to restore coronary blood flow and increase myocardial salvage, and thereby to minimize infarct size. However, after the opening of an occluded vessel, reperfusion injury may paradoxically cause additional irreversible myocardial damage that may account for as much as $50 \%$ of the infarct size [13]."

About $30 \%$ to $60 \%$ of patients with STEMI have multivessel coronary artery disease (MVD) [18]." 
STEMI patients with multivessel disease are at high risk for heart failure and cardiogenic shock, [11]." and associated with two time's higher mortality during hospitalization and long- term follow-up,[15]."with a higher incidence of acute coronary syndrome and revascularization after initial intervention [4]."

In patients with STEMI and MVD, incomplete revascularization has been shown to be a strong and independent risk factor for death and major adverse cardiac events (MACE) [6]." In contrast, complete revascularization has been associated with better long-term prognosis [4]."

Treatment strategies vary widely from an aggressive approach which treats all significant lesions in the acute phase of primary PCI to a conservative approach with primary PCI of only the infarct-related artery (IRA) and subsequent medical therapy unless recurrent ischaemia occurs. Between these two extremes are other alternatives; mainly that of staged procedures with the IRA treated acutely and other lesions treated later during the hospital stay or within the first month following discharge. There is no randomized data to definitely answer the issues about the specific scientific merits of any of these approaches. However, there are increasing data from observational series. Each approach has advantages and disadvantages [18]."

In the literature, PCI for STEMI should be limited to the culprit lesion except in patients with cardiogenic shock [16]."

In congruence with the clinical guidelines, several metaanalyses of observational and non-randomised studies show no benefit from PCI of the non-infarct artery [17]."

However, conclusions from those non-randomised and observational studies are limited by the potential for selection bias [12].”

Primary PCI should not be performed in a noninfarct artery at the time of primary PCI in patients with STEMI who are hemodynamically stable and PCI is reasonable in a noninfarct artery at a time separate from primary PCI in patients with intermediate or high-risk findings on noninvasive testing. [13]."

Acute PCI of IRA followed by staged PCI of secondary lesions can optimize potential for complete revascularization and stable stenosis might be intervened more safely at a later phase, after stabilization, while main disadvantages are economics, treating asymptomatic lesions, complications of treating secondary lesions early after index event and the uncertainty of timing [18]."

CvLPRIT (the 2015 Complete Versus Lesion-Only Primary PCI trial) is a U.K multicenter, randomized, openlabel trial, which set out to test the feasibility, safety, and potential benefit of undertaking in-hospital complete revascularization of angiographically significant N-IRA lesions in patients presenting with P-PCI for STEMI compared with percutaneous coronary intervention (PCI) of the infarct-related artery (IRA) alone. The hypothesis was that early treatment of significant N-IRA lesions during the index admission would reduce global ischemic burden and protect against short- and medium-term recurrent ischemic events. CvLPRIT and PRAMI ask a similar question but were initiated independently and with definitive differences in trial design [7]."

The optimal management of patients found to have multivessel disease who undergoing primary percutaneous coronary intervention (P-PCI) for ST-segment elevation myocardial infarction specially in diabetic patients remains unresolved, so our study aims to evaluate short term follow up for diabetic patient with acute STEMI undergoing preventive PCI

\section{Patients and Methods}

\subsection{Study Design}

Our study was a prospective, observational study conducted at multicenter hospitals included 120 diabetic patients admitted with acute STEMI and multivessels CAD at National Heart Institute, Menofia university hospital and some private hospitals patients from June 2017 to august 2018 divided into two groups, Group (A) Consisted of 70 diabetic patients with acute STEMI undergone preventive PCI in whom PCI will be done for culprit \& non culprit lesions, Group (B) Consisted of 50 diabetic patients with acute STEMI undergone PCI for culprit lesion only.

\subsection{Methods}

All included patients were subjected to complete and detailed medical history, laboratory investigations, resting standard 12 leads electrocardiogram and trans thoracic echocardio-graphy.

\subsection{In Hospital Outcome}

Major adverse cardiac events (MACE), Hospital readmission, Arrhythmias, Cardiogenic shock, Bleeding, Contrast induced nephropathy, Cerebro vascular stroke.

\subsection{Follow up Patient for 6 Month}

Symptom and signs of heart failure, Cardiac death, recurrence of anginal symptom, Occurrence of myocardial infarction, Hospital readmission, Target vessel revascularization (repeat PCI or bypasses surgery), echocardiography was done at 6 months.

\section{Results}

There were non-significant difference between total revascularization PCI and culprit artery PCI in risk factors as smoking; $34(48.6 \%)$ vs $27(54.0 \%) \mathrm{p}=0.558$, hypertension; $29(41.4 \%)$ vs. $20(40.0 \%), \mathrm{p}=0.875$, diabetes; IDDM 16 $(22.9 \%)$ vs 7 (14.0\%), NIDDM 54 (77.1\%) vs $43(86.0 \%)$, $\mathrm{p}=0.224$, dyslipidemia; $29(41.4 \%)$ vs. $22(44.0 \%), \mathrm{p}=0.779$, family history of CAD; $13(18.6 \%)$ vs $9(18.0 \%), \mathrm{p}=0.936$ and were statistically non significant between the two groups

Initial TTE was undertaken at amedian of 12 hours in both treatment arms, The ejection fraction was similar in both groups; $51.76 \pm 3.71$ in total revascularization PCI and 
$51.62 \pm 4.95$ in the culprit artery PCI, $p=0.863$ but there was statistically significant difference between groups according to diastolic function $\mathrm{p}=0.042^{*}$.

Double vessel disease was present in $106(88.8 \%)$ patients and triple vessel disease occurred in $14(11.7 \%)$ patients, there were statistically non-significant differences between total revascularization PCI and culprit artery PCI as CAD extent.

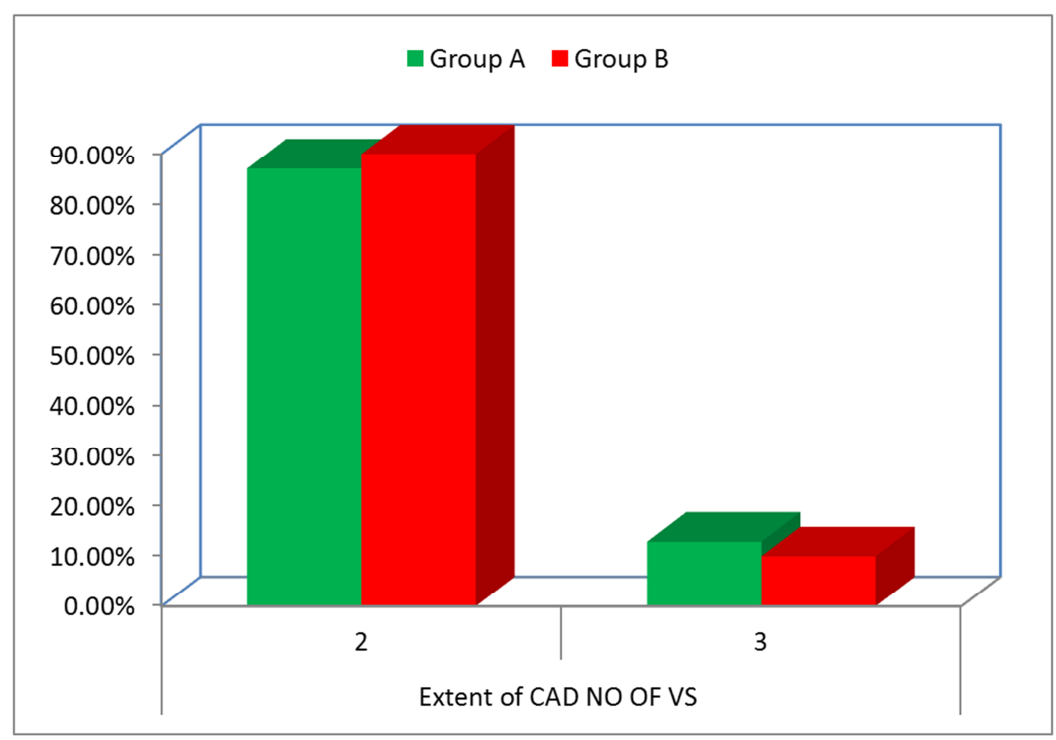

Figure 1. Bar chart between group A and group B according to extent of CAD no of VS.

Successful PCI procedure result was achieved in 67 $(95.7 \%)$ of total revascularization group, compared with 49 $(98.0 \%)$ in the culprit artery group, $\mathrm{p}=0.492$.
There was statistically significant difference in: Contrast amount $229.43 \pm 249.35$ vs $157.60 \pm 15.19, \mathrm{p}=0.044^{*}$

Table 1. Comparison between group A and group B according to PCI strategy.

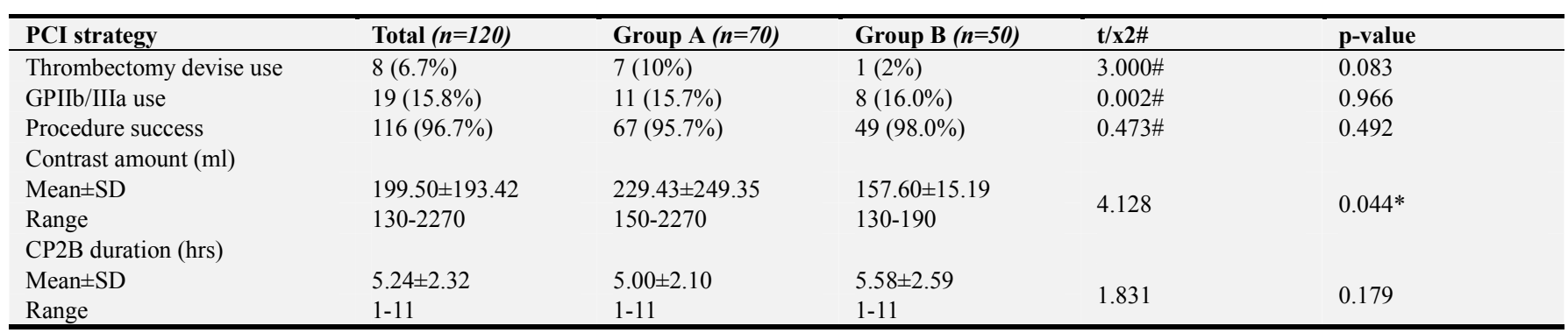

There were no cases referred to urgent CABG in the two groups, Other in hospital complications were variable, but none of them were statistically significant between the total revascularization PCI and culprit artery PCI; major bleeding $(0 \%$ vs $2 \%, \mathrm{p}=0.235), \operatorname{CIN} 3(4.3 \%)$ vs $1(2.0 \%), \mathrm{p}=0.492,4$ patients developed cardiogenic shock after the primary PCI; $1(1.4 \%)$ vs $3(6 \%) \mathrm{p}=0.169$, There were no statistically significant differences between the groups with regard to inhospital mortality or the incidence of complications.

Clinical follow-up was performed for six months. Patients were seen at $6^{\text {th }}$ month to document major adverse cardiac events (MACE) comprising mortality, recurrent MI, heart failure (HF), and ischemic-driven revascularization by PCI or
CABG. All deaths cardiac- related unless they could be clearly attributed to another cause, as determined by the clinical events. Despite the six month cardiac mortality tended to be decreased in the total revascularization group but this decrease was no significant $1(1.4 \%)$ vs. $2(4.0 \%), p=$ 0.374 between the total revascularization and culprit PCI respectively. There was no increase in recurrent MI, (STEMI; $2(2.9 \%)$ vs. $2(4.0 \%) \mathrm{p}=0.731$, HF $4(5.7 \%)$ vs $7(14.0 \%) \mathrm{p}=$ 0.121 between the total revascularization and culprit PCI respectively. The total revascularization group were significantly less suffering from refractory angina 5 (7.1\%) vs $15(30.0 \%), p=<0.001$ and less re-hospitalized for cardiac causes $14(20.0 \%)$ vs $22(44.0 \%), p=0.005$,

Table 2. Comparison between group A and group B according to after 6 months outcome after hospital discharge.

\begin{tabular}{|c|c|c|c|c|c|}
\hline After 6 months Outcome after Hospital Discharge & Total $(n=120)$ & Group A $(n=70)$ & Group B $(n=50)$ & $\mathbf{x 2}$ & p-value \\
\hline \multicolumn{6}{|l|}{ Ccu stay (days) } \\
\hline $\mathrm{Mean} \pm \mathrm{SD}$ & $4.81 \pm 1.59$ & $4.63 \pm 1.36$ & $5.06 \pm 1.85$ & $t=2170$ & 0143 \\
\hline Range & $3-12$ & $4-12$ & $3-11$ & $\mathrm{t}=2.1 / 0$ & 0.143 \\
\hline Cardiac death & $3(2.5 \%)$ & $1(1.4 \%)$ & $2(4.0 \%)$ & 0.791 & 0.374 \\
\hline
\end{tabular}




\begin{tabular}{|c|c|c|c|c|c|}
\hline After 6 months Outcome after Hospital Discharge & Total $(n=120)$ & Group A $(n=70)$ & Group B $(n=50)$ & $\mathbf{x 2}$ & p-value \\
\hline STEMI & $4(3.3 \%)$ & $2(2.9 \%)$ & $2(4.0 \%)$ & 0.118 & 0.731 \\
\hline $\mathrm{CHF}$ & $11(9.2 \%)$ & $4(5.7 \%)$ & $7(14.0 \%)$ & 2.405 & 0.121 \\
\hline Refractory Angina & $20(16.7 \%)$ & $5(7.1 \%)$ & $15(30.0 \%)$ & 10.971 & $<0.001 * *$ \\
\hline $\mathrm{CABG}$ & $3(2.5 \%)$ & $1(1.4 \%)$ & $2(4.0 \%)$ & 0.791 & 0.374 \\
\hline TVR & $9(7.5 \%)$ & $6(8.6 \%)$ & $3(6.0 \%)$ & 0.278 & 0.598 \\
\hline Rehospitalization for cardiac cause & $36(30.0 \%)$ & $14(20.0 \%)$ & $22(44.0 \%)$ & 8.000 & $0.005 *$ \\
\hline
\end{tabular}

\section{Discussion}

PCI is currently the treatment of choice in patients with STEMI. CAD is a diffuse process and patients presenting with a coronary syndrome in $20-40 \%$ of cases have multiple significant coronary lesions, which confer a substantially increased risk of cardiovascular morbidity and mortality.

Recent studies, suggest that acute coronary syndromes, including AMI, may result from a systemic inflammatory process, causing multiple unstable lesions. Thus, a strategy of multivessel PCI in the peri-infarct period may be important in improving the outcomes of primary angioplasty, The present study was designed to compare the clinical outcomes of total revascularization PCI group A (culprit and nonculprit artery PCI during the index primary procedure) with culprit artery PCI group B in haemodynamically stable diabetic patients with STEMI and multi-vessel CAD.

Successful PCI procedure result was achieved in 67 $(95.7 \%)$ of total revascularization group, compared with 49 $(98.0 \%)$ in the culprit artery group, $\mathrm{p}=0.492$.

Our definition was according to $2011 \mathrm{ACCF} / \mathrm{AHA} / \mathrm{SCAI}$ Guideline for PCI and agreed with; that a successful PCI should achieve angiographic success without associated inhospital major clinical complications (e.g., death, MI, stroke, emergency CABG).

In hospital mortality was $1.7 \%$ ( 2 patients in group B). In A. R Santos et al 2014 , over all mortality was $5.2 \%$ with non significant difference $7.8 \%$ vs $2.6 \%$ between the two groups. This may be explained by small number of our studied patients (100) vs (257) in A. R Santos et al 2014, Performing complete revascularization has been shown to result in greater use of contrast, prolonged procedural time and increased exposure to radiation especially when performed at the same time as the index primary PCI for the culprit lesion. Gershlick AH, et al 2015.

Six month cardiac mortality tended to be decreased in the preventive group but this decrease was not significant factor $1.4 \%$ vs $4 \%, p=0.374$. There was no non-cardiac mortality in both groups. Onfollow up, there was no increase in reinfarction (STEMI; $2.9 \%$ vs $4 \% \mathrm{p}=0.731$ ). The preventive group were significantly, less suffering from refractory angina $(7.1 \%$ vs $30 \% \mathrm{p}=0.001)$ and drived by the significant reduction of rehospitalization for cardiac cause in the preventive PCI $(20 \%$ vs $44 \% \mathrm{p}<0.005)$.

Based on individual and careful patient and lesion assessments, preventive PCI can be done safely with less need to further revascularization, and reduced risk of refractory angina in STEMI with MVD.

\section{Study Limitations}

First: The present study was not a randomized controlled trial, and a selection bias may have existed.

Second: Small sample size, which reduces the statistical validity of some of the differences between the groups.

Third: The criteria used by different operators to decide between culprit artery PCI and preventive PCI are not specified, which also weakens the validity of some of the results obtained.

Fourth: The present study did not use functional assessment of non-culprit artery lesion severity by FFR rather than depending on conventional angiography.

\section{Conclusion \& Recommendations}

The total revascularization PCI appears to be safe as culprit artery PCI with effective reduction of refractory angina and repeated revascularization but no benefit on mortality or recurrent MI in selected hemodynamically stable STEMI diabetic patients with multivessel disease.

\section{References}

[1] A. R. Santos, B. C. Pi carra, M. Celeiroetal. Multi-vessel approach in ST- elevation myocardial infarction: Impact on in-hospital morbidity and mortality. Rev Port Cardiol. 2014; 33: $67-73$.

[2] Bhatt DL, Eagle KA, Ohman EM, et al; REACH Registry Investigators. Comparative determinants of 4-year cardiovascular event rates in stable outpatients at risk of or with atherothrombosis. JAMA. 2010; 304: 1350-1357. doi: 10.1001/jama.2010.1322.

[3] Bates E. R. Tamis-Holland J E, Bittl JA, et al. PCI Strategies in Patients with ST-Segment Elevation Myocardial Infarction and Multi-vessel Coronary Artery Disease. J Am CollCardiol. 2016; 68 (10): 1066-81.

[4] Gershlick AH, Khan JN, Kelly DJ, et al. Randomized trial of complete versus lesion-only revascularization in patients under- going primary percutaneous coronary intervention for STEMI and multi-vessel Disease: the CvLPRIT trial. J Am CollCardiol. 2015; 65: 963-72.

[5] Goldstein JA, Demetriou D, Grines CL, et al. Multiple complex coronary plaques in patients with acute myocardial infarction. N Engl J Med, 2000; 343: 915-922.

[6] Kalarus Z, Lenarczyk R, Kowalczyk J, et al. Importance of complete revascularization in patients with acute myocardial infarction treated with percutaneous coronary intervention. Am Heart J 2007; 153: 304-312. 
[7] Keeley EC, Boura JA and Grines CL. Primary angioplasty versus intravenous thrombolytic therapy for acute myocardial infarction: a quantitative re- view of 23 randomized trials. Lancet. 2003; 361: 13-20.

[8] Lee HW, Hong TJ, Yang Mi J, et al. Comparison of infarctrelated artery vs multivessel revascularization in ST-segment elevation myocardial infarction with multivessel disease: analysis from Korea Acute Myocardial Infarction registry (KAMIR). Cardiol J 2012; 19, 3: 256-266.

[9] Levine GN, O'Gara PT, Bates ER, et al. 2015 ACC/AHA/SCAI focused update on primary percutaneous coronary intervention for patients with ST- elevation myocardial infarction: an update of the 2011 ACCF/AHA/SCAI Guideline for Percutaneous Coronary Intervention and the 2013 ACCF/AHA Guideline for the Management of ST- Elevation Myocardial Infarction. J Am Coll Cardiol 2015; 67: 1235-50.

[10] Mc Cann G, Khan JN, Greenwood JP, et al. Complete Versus Lesion- Only Primary PCI The Randomized Cardiovascular MR CvLPRIT Sub study. J Am Coll Cardiol 2015; 66: 2713 24.

[11] Muller DW, Topol EJ, Ellis SG, et al. Multivessel coronary artery disease: a key predictor of short- -term prognosis after reperfusion therapy for acute myocardial infarction (TAMI) Study Group. Am Heart J, 1991; 121: 1042-1049.

[12] Nallamothu BK, Hayward RA, Bates ER. Beyond the randomized clinical trial: the role of effectiveness studies in evaluating cardiovascular therapies. Circulation 2008; 118: 1294-303.
[13] O'Gara PT, Kushner FG, Ascheim DD, et al. 2013 ACCF/AHA guideline for the management of ST-elevation myocardial infarction: a report of the American College of Cardiology Foundation/American Heart Association Task Force on Practice Guidelines. Circulation. 2013; 127: 529-55.

[14] Qarawani D, Nahir M, Abboud M, et al. Culprit only versus complete coronary revascularization during primary PCI. Int J Cardiol. 2008; 123: 288-92.

[15] Sorajja P, Gersh BJ, Cox DA, et al. Impact of multi-vessel disease on reperfusion success and clinical outcomes in patients undergoing primary percutaneous coronary intervention for acute myocardial infarction. Eur Heart J 2007; 28: 1709-16.

[16] Steg PG, James SK, AtarD, et al. ESC Guidelines for the management of acute myocardial infarction in patients presenting with ST-segment elevation. Eur Heart J 2012; 33 (20): 2569-2619.

[17] Vlaar PJ, Mahmoud KD, Holmes DR, et al. Culprit vessel only versus multi-vessel and staged percutaneous coronary intervention for multi-vessel disease in patients presenting with ST-segment elevation myocardial infarction: a pairwise and network meta-analysis. J Am Coll Cardiol. 2011; 58: 692703.

[18] Widimsky P, Holmes DR, Jr. How to treat patients with ST elevation acute myocardial infarction and multi-vessel disease? Eur Heart J 2011; 32: 396-403. 